This item was submitted to Loughborough's Research Repository by the author.

Items in Figshare are protected by copyright, with all rights reserved, unless otherwise indicated.

\title{
Reply to Sealey and Carter on realism and language
}

PLEASE CITE THE PUBLISHED VERSION

http://dx.doi.org/10.1111/jtsb.12042

\section{PUBLISHER}

(C) 2013 John Wiley \& Sons Ltd

\section{VERSION}

AM (Accepted Manuscript)

\section{PUBLISHER STATEMENT}

This work is made available according to the conditions of the Creative Commons Attribution-NonCommercialNoDerivatives 4.0 International (CC BY-NC-ND 4.0) licence. Full details of this licence are available at: https://creativecommons.org/licenses/by-nc-nd/4.0/

\section{LICENCE}

CC BY-NC-ND 4.0

\section{REPOSITORY RECORD}

Elder-Vass, Dave. 2019. "Reply to Sealey and Carter on Realism and Language". figshare. https://hdl.handle.net/2134/17422. 


\title{
Reply to Sealey and Carter on realism and language
}

\author{
Dave Elder-Vass
}

d.elder-vass@lboro.ac.uk

Note: This is a pre-publication version of a paper published in the Journal for the Theory of Social Behaviour. It may differ slightly from the published version. Please cite as: Elder-Vass, D. (2014) 'Reply to Sealey and Carter on Realism and Language', Journal for the Theory of Social Behaviour, 44:3, 282-7, and refer to the published version for the final wording and pagination.

\section{Introduction}

Your response nicely illustrates the point that there is more than one way to be a realist about language. You certainly deploy greater knowledge of applied linguistics than I am able to, but my original piece is also necessarily brief on details due to an ambition to cover a broad range of issues. This lack of detail is perhaps one reason why you seem to misunderstand several aspects of my argument and I therefore welcome the opportunity to clarify it.

\section{Ontology and theory}

In counterposing the theories of linguistic systems and norm circles as starkly as you do, you perhaps obscure that there are two different kinds of issue to be considered here. The first, and that upon which the original paper focussed, is whether each of these concepts corresponds to some real and causally potent force. This is not an either/or choice: in principle one, both, or neither of these two concepts might refer to a causally powerful class of forces.

To justify the claim that either is causally significant we need an explanation of the material form of entities of the type concerned and the mechanism by which such entities could produce the powers claimed for them. I have gone to some lengths elsewhere to demonstrate the material structures and causal mechanisms behind my claims for norm circles (Elder-Vass, 2010; Elder-Vass, 2012). However, I have not yet seen an adequate account of the material basis of the entities that you call linguistic systems and of the mechanisms by which such systems could have the powers claimed for them, if these systems take a form similar to Popper's World 3 and Archer's adaptation of this for her Cultural System. I do indeed reject the claim that "ideas are sui generis real". Ideas exist as mental properties of human individuals. Texts such as books are material objects that, in conjunction with our grasp of linguistic practices, can be used to communicate ideas (imperfectly but often very effectively), and may therefore play an important part in transmitting 
both information and normative pressures. As a consequence they play a significant role in (contingently and imperfectly) aligning our beliefs and dispositions, but at no point in the process of writing or reading is there an idea or a linguistic system that exists outside our heads.

This is not to say that all versions of the concept of linguistic systems are necessarily empty of empirical content. Perhaps the most plausible version of the concept would refer to the form taken by a set of interlinked linguistic dispositions when those dispositions exist in a human individual, particularly if we could identify systematic similarities in such systems across multiple individuals. Such similarities in turn would need to be explained, and one might expect them to be the product of a combination of innate similarities in our capacities and similar environmental pressures (including the influence of norm circles). Perhaps a concept like this could do some of the work that you want a linguistic system to do, but it is not something that exists outside the heads of the individuals concerned.

The second issue is the question of which forces actually contribute to the causation of particular events. Scientific realism implies that events are caused by multiple interacting powers; linguistic events could be caused, for example, by the interacting causal powers of human individuals, including their innate linguistic capacities, of linguistic norm circles (operating through the effects that our experience of past normative pressure has on our neural networks and thus our linguistic dispositions), and indeed the non-linguistic material and social context. Hence, neither linguistic systems nor norm circles could be universal and complete explainers of all or indeed any linguistic phenomena, and I certainly do not make such claims for norm circles, as you seem to suggest I do. For any given linguistic phenomenon, the correct causal explanation may involve many other factors as well as either (or, logically, both) of these. The claim that some aspects of language use are causally influenced by linguistic norms does not entail that all aspects of it are determined by those norms. I am therefore just as happy as you to recognise, for example, the lengthy historical processes, the contributions of individual language users and interactions, the artefacts and the political interests that contribute to the development and maintenance of language. Your discussion of these issues is just one of many cases in which you appear to cite interesting and worthwhile arguments about language as if they undermined my case when there is no obvious reason to think they are incompatible with it. Nor, for a further example, do my views on the causal powers behind language entail that it does not provide a set of resources that people can and do use to do many, often creative, things.

\section{Clarifying norm circles}

Several of your comments depend on reading my account of norm circles in ways that I did not intend, including some that I have explicitly contradicted elsewhere.

1) You suggest that there are methodological problems with the concept of a norm circle. As the original paper made clear, "A norm circle is the group of people who are committed to supporting a particular norm, by endorsing and enforcing it in their relations with others". This is a phenomenon that is clearly open to empirical investigation, for example by interviewing subjects about their experience of norm 
endorsing behaviour, who they felt had influenced their own acceptance or rejection of a norm, whether they felt when endorsing a norm that they did so with the backing of some wider force, how wide they felt the group of people supporting the norm was, whether they had experienced evidence of conflicting norms in other social environments, and so on. This does raise methodological questions, though not, on the whole, the ones that you suggest. There is rather a subtle issue, for example, over the question of whether merely conforming to a norm constitutes endorsing it; given the extent to which we appear to build our sense of the normative environment on the basis of observed behaviour, it may often be the case that it does. This does not mean, however, that a norm circle is defined by conforming behaviour. First, it is defined in terms of endorsing and not conforming, and there are other types of endorsing behaviour that are also important: notably praising, rewarding, criticising, and punishing. Second, there are cases where people conform to norms while expressing their disapproval of them, thus placing themselves outside the norm circle concerned. Third, norm circles are defined in terms of commitment, in a sense that entails a tendency to endorsing behaviour, but like all other causal tendencies this one may be frustrated in particular cases. I may believe it is wrong to steal but refrain from trying to endorse or enforce this norm when faced with a mugger brandishing a knife. I may believe that a certain grammatical construction is outdated and inappropriate, but refrain from saying so when it is used by someone in a position of authority over me. Empirical identification of who is and is not a member of a given norm circle is therefore challenging but not necessarily impossible. The issues discussed above would require careful attention to a series of complexities, and there may be borderline cases on which it is difficult to make a principled judgement. But there are empirical difficulties in identifying the boundaries of many phenomena and realists accept that causal powers may not be empirically obvious. These challenges therefore do not constitute an argument that norm circles do not exist, cannot be researched, or are not causally effective.

2) A second feature of the definition referred to above is that norm circles support "a particular norm". Norm circles are associated with individual norms, such as 'avoid double negatives' and 'you should not steal'. I have never suggested, for example, that "speakers of English" or "the Catholic Church" are norm circles, so arguments about the nature of such groups cannot plausibly be considered as undermining the concept of norm circles. It is rather odd to suggest that I "have to abandon the notion of the norm circle or decide that a large institution is composed of many different, possibly competing and probably not consistent, norm circles" since the latter has always been my clearly stated position, at least in the sense of institution that is being used here. The Catholic Church is an organisation, and one that is implicated in a complex and sometimes contradictory way in a large number of normative practices. As I have agued elsewhere, organisations are a different kind of social structure than norm circles, although they are interdependent with norm circles in some interesting ways (Elder-Vass, 2010: chapter 7). Turning to the practices of English speakers, these are, as you point out, widely divergent and often in conflict. This is, in fact, a strength of the norm circle concept, as opposed to concepts like the speech community, which remains rather widespread in sociolinguistics, since I argue that there is a separate norm circle for each linguistic 
norm and that any given 'community' may include norm circles endorsing a variety of divergent and even conflicting norms (Elder-Vass, 2012: chapter 6). It is difficult to see how this diversity could be explained by any conception of language that places explanatory power in a single unified element, such as a speech community or a linguistic system.

3) One reading of norm that perhaps contributes to these misunderstandings is the obsolete Parsonian functionalist idea that norms are always stabilisers of the established social system, and thus that all norms are official ones established by powerful interests. My view is that there are norm circles for official linguistic norms and for linguistic norms that help to sustain systems of stratification, but there are also norm circles for linguistic norms that are positively disruptive of official norms and systems of power. ${ }^{1}$ Amongst English speakers, for example, there is a norm circle for 'use double negatives' as well as one for 'avoid double negatives', and these are in competition with each other. The concept of norm circles entails no judgement as to which of these is more valid in any respect.

4) As you point out, my previous work on language has been more oriented to signs than to grammar (Elder-Vass, 2012: chapters 5-7). Following Chomsky, you suggest that grammar is not open to normative explanations and needs, rather, to be explained as the product of our innate language capacity. As the original paper made clear, I do see innate features of the brain as one important factor contributing to our grammatical competence and practices, but there is also a social influence on grammar. Of course, if we define grammar as that element of our innate capacities that sustains all humanly possible syntactic structures then it cannot be socially influenced. But if we take grammar to be the actual rules that we follow (subconsciously, on most occasions) in constructing sentences then they are clearly normative: most obviously, they are different amongst speakers of different languages, and they are sustained by systems of linguistic education and normative pressures. This is entirely compatible with recognising that the range of viable grammatical practices is both constrained and enabled by an innate language capacity. We need both the innate capacity and the norm circles to explain which grammatical practices actually prevail in any given social context, and indeed other causal factors may influence this too. These may include, for example, which ways of speaking are physically easier given our biology, the use of various ways of speaking as indicators of status, and technical developments.

5) This brings us to the question of explaining linguistic change. While it is true that "norm circles work better as explanations of morphostasis than of morphogenesis" this does not constitute a problem for the theory, for at least two reasons. First, given a world in which events are multiply determined, we can recognise that other factors may play a leading role in linguistic change without this impacting on the argument that norm circles play a central role in sustaining linguistic stability and indeed spreading new practices. To take one of the simpler cases, some new words are developed to name new inventions, and spread as knowledge and experience of

\footnotetext{
${ }^{1}$ Cresswell, Karimova and Brock express this point nicely by contrasting hegemonic norm circles with norm circles of resistance (forthcoming).
} 
those inventions spread. This process is no doubt supported by the development of norm circles that advocate use of the new word (and perhaps discourage the use of others) to refer to the invention, but the original linguistic innovation is not a product of such a norm circle, nor is the spreading need for an appropriate word. Secondly, the diverse intersectionality of norm circles in the contemporary world is a positive enabler of normative change. If there were only one speech community or one linguistic system governing our use of language, it is difficult to see how linguistic innovation could proceed, but if there are multiple, potentially competing, norm circles, than change can proceed through a process in which one norm circle gains influence at the expense of another. These issues are discussed at more length (though not for specifically linguistic cases) in earlier work (Elder-Vass, 2010: 133-8).

\section{Conclusion}

This short and necessarily incomplete reply has sought to correct some of the misunderstandings of norm circles implicit in your response and to reinforce some doubts over your version of the linguistic system, as I understand it. $^{2}$ Norm circles, it argues, provide an important part of the explanation for linguistic practices, but always in conjunction with other interacting causal powers.

\section{References}

Cresswell, M., Karimova, Z., \& Brock, T. (forthcoming). 'Feminism, Psychiatric Survivors and the Problematisation of Self-Harm in the UK, 1980-2000'.

Elder-Vass, D. (2010). The Causal Power of Social Structures. Cambridge: Cambridge UP.

Elder-Vass, D. (2012). The Reality of Social Construction. Cambridge: Cambridge UP.

\footnotetext{
${ }^{2}$ One issue I am conscious of neglecting is the question of what 'a language' could be. On this, the reader is referred to the discussion of cultures, and the brief extension of this to languages, in ElderVass (2012: 159-173).
} 